Review

\title{
Fowler's Syndrome-The Cause of Urinary Retention in Young Women, Often Forgotten, but Significant and Challenging to Treat
}

\author{
Jacek K. Szymański *(D), Aneta Słabuszewska-Jóźwiak (D) and Grzegorz Jakiel
}

check for

updates

Citation: Szymański, J.K.;

Słabuszewska-Jóźwiak, A.; Jakiel, G.

Fowler's Syndrome-The Cause of

Urinary Retention in Young Women,

Often Forgotten, but Significant and Challenging to Treat. Int. J. Environ.

Res. Public Health 2021, 18, 3310.

https://doi.org/10.3390/

ijerph18063310

Academic Editor: Artur Wdowiak

Received: 30 January 2021

Accepted: 21 March 2021

Published: 23 March 2021

Publisher's Note: MDPI stays neutral with regard to jurisdictional claims in published maps and institutional affiliations.

Copyright: (c) 2021 by the authors. Licensee MDPI, Basel, Switzerland. This article is an open access article distributed under the terms and conditions of the Creative Commons Attribution (CC BY) license (https:// creativecommons.org/licenses/by/ $4.0 /)$.
First Department of Obstetrics and Gynecology, Centre of Postgraduate Medical Education, Żelazna 90 Str., 01-004 Warsaw, Poland; anetaslabuszewska@gmail.com (A.S.-J.); grzegorz.jakiel1@o2.pl (G.J.)

* Correspondence: jkszymanski2@gmail.com; Tel.: +48-601243792

\begin{abstract}
Urinary retention in young women is a relatively rare clinical problem and is often underdiagnosed. In particular, functional causes of urinary retention pose a diagnostic challenge. One of them is Fowler's syndrome, which is associated with impaired urethral relaxation. Fowler's syndrome is characterized by a large bladder capacity, reduced sensation, increased maximal urethral closure pressure, and detrusor underactivity. Several hypotheses have arisen to explain the cause of urethral relaxation disorders: hormonal changes characteristic of Polycystic Ovary Syndrome (PCOS), causing abnormal stabilization of the muscle membrane, primary failure of relaxation of the striated muscle of the urethra sphincter, and increased urethral afferent activity, inhibiting the bladder afferent signals from reaching the brain by potentiating a spinal mechanism of urinary continence. Currently, sacral neuromodulation is the only intervention that can restore an atypical voiding pattern in women with Fowler's syndrome. The therapeutic effectiveness exceeds 70\%, although the revision rate is relatively high, exceeding 50\%. Well-designed, long-term prospective studies comparing sacral neuromodulation (SNM) with other therapies such as pelvic floor muscle physiotherapy are warranted to offer the best patient-tailored treatment.
\end{abstract}

Keywords: urinary retention; Fowler's syndrome; sacral neuromodulation

\section{Introduction}

Urinary retention in young women is a relatively rare clinical problem. Epidemiological studies estimate that its incidence in young women ranges from 3 cases per 100,000 per year to $0.3 \%$ after the exclusion of other causes, such as postoperative, postpartum, gynecological, urological, rectal, and psychiatric causes [1-3]. The incidence of Fowler's syndrome is rated at 0.2 cases per 100,000 per year [4].

Urinary retention could be related to bladder outlet obstruction (BOO) or detrusor underactivity (DUA), or it may constitute a combination of these two causes. The underlying pathology could be associated with anatomical, neurogenic, and myogenic factors, or it may result from pharmacotherapy or functional reasons where no organic cause is identified. [5]. The anatomical (mechanical) factors include, among others, pelvic organ tumors, stenosis of the bladder neck, urethral diverticulum, pelvic organ prolapse, and previous pelvic surgery. The functional causes are a result of the pathological changes in the contraction of the periurethral muscles (dysfunctional voiding and detrusor sphincter dyssynergia) or impaired urethral relaxation (Fowler's syndrome) [6]. Urinary retention caused by mechanical BOO is usually successfully treated with medication or surgery, whereas the management of urinary retention resulting from detrusor underactivity or functional BOO remains a challenge. However, urinary retention caused by DUA as a consequence of pharmacotherapy is usually transient and reversible [5]. This study aimed to review the literature on the current knowledge of Fowler's syndrome with consideration of sacral neuromodulation as a modern therapeutic method. 


\section{Materials and Methods}

A literature search was performed in August 2020 using the Medline and Embase databases, ranging from 1988 to February 2021. The adopted criteria allowed for the inclusion of studies on humans and animals, original papers, and prospective and retrospective trials limited to those published in English. Studies on the effectiveness of neuromodulation in the treatment of Fowler's syndrome were identified using various medical subject headings. The search for relevant records was carried out using the following phrases: "Fowler's syndrome", "Fowler's syndrome and sacral neuromodulation", "urinary retention in women", and "urinary retention in women and sacral neuromodulation".

\section{Results}

A total of 2618 articles were identified. Articles in languages other than English, duplicates, articles available only in the form of abstracts, and papers not closely related to the subject of this study were excluded. Ultimately, 25 articles were selected. This included ten original studies, two prospective studies, two retrospective studies, one retrospective and subsequently prospective trial, and one case-control study. Moreover, five literature reviews and one case report were included (Figure 1).

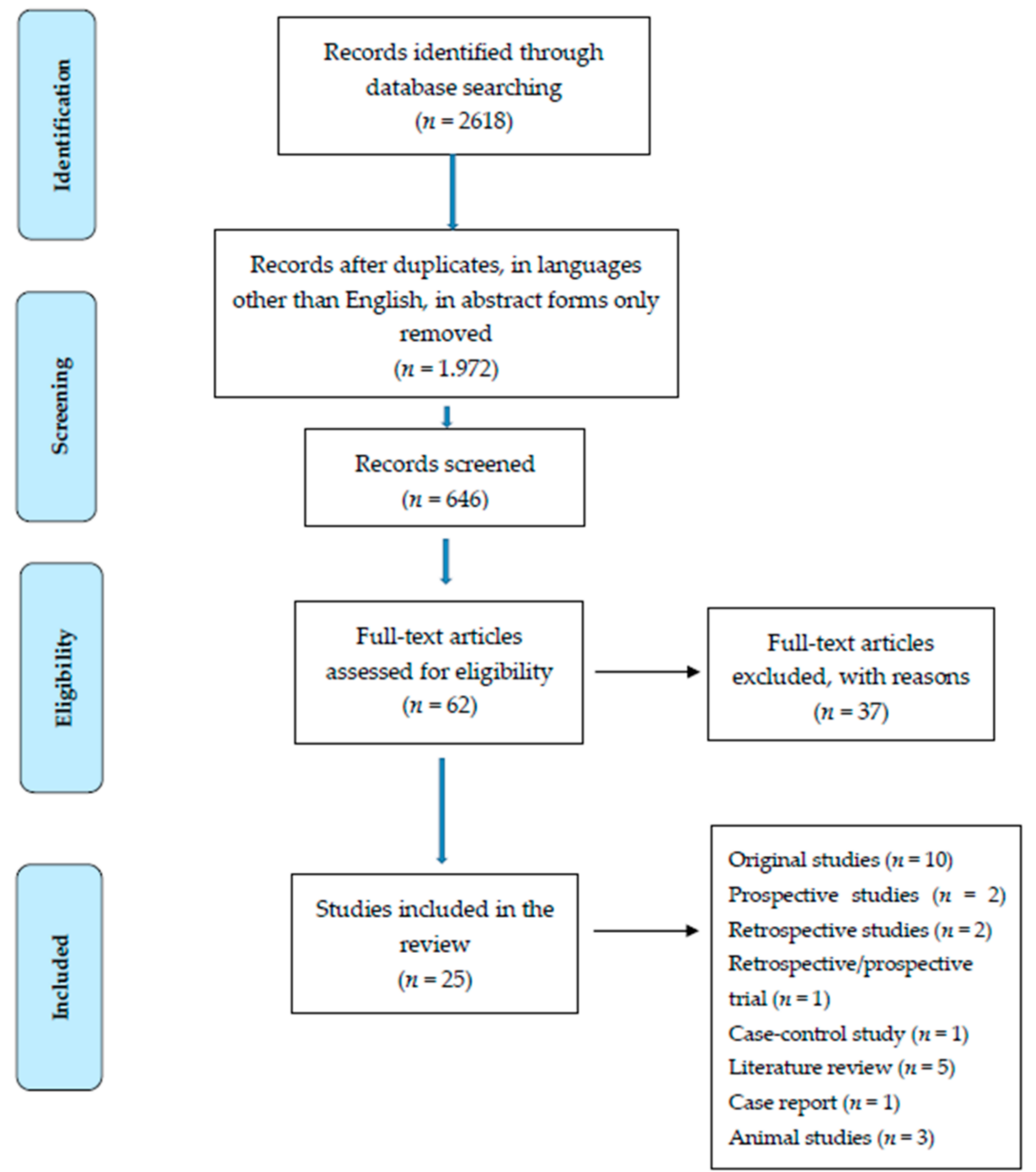

Figure 1. Flow chart presenting the process of searching for the eligible articles.

Three of the studies had been conducted on animals. The number of participants in the original studies varied and ranged from 6 to 87. In retrospective and prospective 
studies, the number of subjects ranged from 18 to 138 , with a mean follow-up of 13.5 years (12-15 years) and 10.5 months (9-12 months), respectively. The relevant studies are listed in Table 1.

Table 1. Original studies on sacral neuromodulation. PCOS-Polycystic Ovary Syndrome, CRDs—complex repetitive discharges, DBs—decelerating bursts, EUS — external urethral sphincter, TRUS—-transrectal ultrasonography, SNM —sacral neuromodulation, FS—Fowler's syndrome, PAG—periaqueductal grey, DRS—dorsal root stimulation, INUR—idiopathic nonobstructive urinary retention, TNS—tibial nerve stimulation, PNS—pudendal nerve stimulation.

\begin{tabular}{|c|c|c|c|}
\hline Author & Type of Study & Aim & Primary Outcome \\
\hline Fowler et al., 1988 & Cross-sectional & $\begin{array}{l}\text { To reveal the cause of unexplained urinary } \\
\text { retention in young women }\end{array}$ & $\begin{array}{l}\text { Abnormal electromyographic activity of the } \\
\text { external urethral sphincter in women with } \\
\text { urinary retention associated with PCOS }\end{array}$ \\
\hline Fowler et al., 1985 & Observational & $\begin{array}{l}\text { To elucidate the electromyotonic activity } \\
\text { of the external urethral sphincter in } \\
\text { women with urinary retention }\end{array}$ & $\begin{array}{l}\text { Complex repetitive discharges and } \\
\text { decelerating bursts, ephaptic spread of } \\
\text { excitation between muscle fibers }\end{array}$ \\
\hline Tawadros et al., 2015 & Cross-sectional & $\begin{array}{l}\text { To investigate the presence of CRDs and } \\
\text { DBs in the EUS during the menstrual cycle } \\
\text { in females with no urinary symptoms }\end{array}$ & $\begin{array}{l}\text { CRDs and DBs in the EUS are present in } 53 \% \\
\text { of asymptomatic women, more commonly in } \\
\text { the luteal phase of the cycle }\end{array}$ \\
\hline Ramm et al., 2012 & Cross-sectional & $\begin{array}{c}\text { To compare the proportion of women with } \\
\text { CRDs among females with and without } \\
\text { urinary disorders }\end{array}$ & $\begin{array}{c}\text { CRDs detected in } 30 \% \text { of asymptomatic } \\
\text { women }\end{array}$ \\
\hline Noble et al., 1995 & Cross-sectional & $\begin{array}{l}\text { TRUS assessments of the EUS volume in } \\
\text { women with obstructed voiding and } \\
\text { abnormal electromyography (EMG) } \\
\text { activity and in asymptomatic women }\end{array}$ & $\begin{array}{c}\text { The volume of the EUS in the control group } \\
\text { was significantly lower than in the obstructed } \\
\text { group }\end{array}$ \\
\hline Andrich et al., 2005 & Cross-sectional & $\begin{array}{l}\text { Morphological description of the urethral } \\
\text { rhabdosphincter in women with and } \\
\text { without urinary retention }\end{array}$ & $\begin{array}{c}\text { No difference in rhabdosphincter fiber } \\
\text { diameter was found in women with urinary } \\
\text { retention and control }\end{array}$ \\
\hline DasGupta, Fowler 2004 & Cross-sectional & $\begin{array}{l}\text { SNM in restoring voiding function in } \\
\text { women with urinary retention }\end{array}$ & $\begin{array}{l}\text { SNM has no direct relaxant effect on the } \\
\text { sphincter }\end{array}$ \\
\hline Kavia et al., 2010 & Etiology (case series) & $\begin{array}{l}\text { To examine brain responses to bladder } \\
\text { filling in women with FS treated with } \\
\text { SNM }\end{array}$ & $\begin{array}{l}\text { Overactive urethra inhibits afferent signals } \\
\text { blocking bladder afferent activity at the sacral } \\
\text { level, deactivates the periaqueductal grey } \\
\text { (PAG) and higher center, causing a loss of } \\
\text { bladder sensation. SNM blocks inhibition by } \\
\text { urethral afferents at the sacral level }\end{array}$ \\
\hline DasGupta et al., 2005 & $\begin{array}{c}\text { Etiology } \\
\text { (cross-sectional) }\end{array}$ & $\begin{array}{l}\text { To investigate how SNM acts on brain } \\
\text { centers involved in bladder function in } \\
\text { women with FS and control }\end{array}$ & $\begin{array}{l}\text { Enhanced limbic cortical activity with no } \\
\text { significant activity in the brainstem was } \\
\text { detected while bladder fulness was present in } \\
\text { women with FS. SNM restores the midbrain } \\
\text { activity and decreases cortical activity in this } \\
\text { group }\end{array}$ \\
\hline Karmarkar et al., 2015 & Case-control study & $\begin{array}{l}\text { To assess the prevalence of gynecological } \\
\text { pathologies in women with FS }\end{array}$ & $\begin{array}{l}\text { Statistically significant relationship between } \\
\text { FS and endometriosis }(p=0.003) \text {, and FS and } \\
\text { PCOS ( } p=0.003) \text {, was found }\end{array}$ \\
\hline Panicker et al.,2012 & $\begin{array}{l}\text { Observation from } \\
\text { Prospective Clinical } \\
\text { Study }\end{array}$ & $\begin{array}{l}\text { To identify the impact of opiates on } \\
\text { urinary retention in women }\end{array}$ & $\begin{array}{c}\text { Exogenous opiates may compound any } \\
\text { functional abnormalities predisposing women } \\
\text { to urinary retention }\end{array}$ \\
\hline Li et al., 2018 & Animal study & $\begin{array}{c}\text { To test the hypothesis that DRS blocks } \\
\text { pudendal afferent inhibition of the } \\
\text { micturition reflex }\end{array}$ & $\begin{array}{l}\text { DRS blocks pudendal afferent inhibition and } \\
\text { restores bladder capacity to control level }\end{array}$ \\
\hline Swinn et al., 2000 & Case-control study & $\begin{array}{c}\text { To evaluate the efficacy of SNM in the } \\
\text { treatment of FS }\end{array}$ & $\begin{array}{c}\text { Success rate } 68 \% \\
\text { Reoperation rate } 21 \%\end{array}$ \\
\hline Mehmood et al., 2017 & Retrospective study & $\begin{array}{l}\text { To determine the safety and efficacy of } \\
\text { SNM in the treatment of INUR }\end{array}$ & $\begin{array}{l}\text { Improvement rate } 83.3 \% \\
\text { Reoperation rate } 41.6 \%\end{array}$ \\
\hline Li et al., 2020 & Animal study & $\begin{array}{l}\text { To determine the effects of TNS on reflex } \\
\text { bladder activity }\end{array}$ & $\begin{array}{l}\text { Repeated application of TNS produced } \\
\text { long-lasting bladder underactivity }\end{array}$ \\
\hline Mohapatra et al., 2021 & Animal study & $\begin{array}{c}\text { To determine the effects of PNS on reflex } \\
\text { bladder activity }\end{array}$ & $\begin{array}{l}\text { Repeated application of PNS resulted in } \\
\text { long-lasting bladder underactivity }\end{array}$ \\
\hline
\end{tabular}




\subsection{Clinical Picture of Fowler's Syndrome}

Fowler's syndrome typically occurs in post-menarche young women in the second and third decades of life. Most of the patients reveal a trigger medical event in their history, such as gynecological surgery or other surgical procedures, childbirth, and acute medical conditions [5]. Trachta et al. reported a case of a 14-year-old girl who developed urinary retention after an uncomplicated laparoscopic appendectomy [7]. Furthermore, before the onset of retention, these women are likely to have had relatively mild voiding dysfunction, such as infrequent voiding or an intermittent stream [8]. Moreover, young women undergo various surgical procedures, such as urethral dilatation, urethrotomy, hysterectomy, myomectomy, and treatment of endometriosis, before a diagnosis of FS is established. As mentioned above, the prevalence of FS in the female population is rare; thus, an awareness of this pathology in the medical community is crucial for making a proper diagnosis. A detailed medical history that can exclude other possible causes of urinary retention is essential. Certain drug groups such as antidepressants, sedatives, and opiates are well-recognized causes of urinary retention [5,9]. Every young woman with urinary retention should undergo a full evaluation of the lower urinary tract with an assessment of neural control. The clinical features of Fowler's syndrome are listed in Table 2.

Table 2. Clinical features of Fowler's syndrome [5].

\begin{tabular}{|c|c|}
\hline Examination & Feature \\
\hline History & $\begin{array}{c}\text { Young women, post-menarche, } 2 \text { nd to } 3 \text { rd decades } \\
\text { Triggering event (surgery, acute illness) } \\
\text { Variable association with PCOS } \\
\text { Painless retention with a large residual volume of urine }(>1000 \mathrm{~mL}) \\
\text { Pain or difficulty most commonly when removing the catheter }\end{array}$ \\
\hline Urological, gynecological, and neurological assessment & No identified structural or neurological cause of urinary retention \\
\hline Urodynamic studies & $\begin{array}{c}\text { Large bladder capacity } \\
\text { Decreased bladder sensation } \\
\text { Reduced or absent detrusor contraction } \\
\text { Reduced or absent flow } \\
\text { Open bladder neck with narrowing in the midurethra/ballooning of } \\
\text { the proximal urethra }\end{array}$ \\
\hline Concentric needle urethral sphincter electromyography & Complex repetitive discharges and decelerating bursts \\
\hline Trans-vaginal sphincter ultrasound & Increased sphincter volume \\
\hline Urethral pressure profilometry & Increased maximal urethral closure pressure \\
\hline
\end{tabular}

\subsection{Pathophysiology of Fowler's Syndrome}

The etiology of Fowler's syndrome remains unclear. One of the contributing factors is possibly the specific hyperactivity of the external urethral sphincter, which can be diagnosed using a concentric needle (electromyography) EMG electrode. Detailed EMG analysis shows that there are two components to sphincter activity: complex repetitive discharges (CRDs) and decelerating bursts [10]. CRDs appear as the direct spread of electrical activity from one muscle to another. They do not originate from neuromuscular transmission but are transmitted via adjacent membranes in parallel waves [10]. In this way, the CRDs create autonomous circuitous excitatory activity, leading to impaired relaxation of the urethral sphincter during voiding [5]. On the other hand, abnormal EMG activity has been found in $30-53 \%$ of healthy, asymptomatic women [11,12]. It is difficult to quantify the "amount" of abnormal EMG activity due to the small diameter of the sphincter muscle fibers and the limitations of the measuring techniques. Based on the observation that women with urinary retention often demonstrate polycystic ovaries, Fowler linked the increased sphincter activity to a hormonal disorder. This hypothesis explains the impaired 
transmission of the electrical impulses throughout the muscle by the improper muscle membrane stability as a consequence of ion channel dysfunction (hormonal channelopathy). In another study, over $80 \%$ of patients with Fowler's syndrome had one or more gynecological disorders. The most prevalent were endometriosis, polycystic ovarian syndrome (PCOS), and subfertility. Although the incidence of these pathologies reached statistical significance, their occurrence in the FS group and the controls stayed within the population range, making the theory of the increased concomitance of FS with other gynecological pathologies tenuous $[13,14]$. Another theory assumes that the primary failure of relaxation of the striated muscle of the urethral sphincter leads to a raised urethral pressure profile. An ultrasound study carried out by Noble et al. [15] in women with obstructed voiding and abnormal sphincter EMG activity found evidence of local muscle hypertrophy. These findings were not confirmed by endoscopic ultrasound biopsy, suggesting that increased sphincter volume could be caused by components other than the skeletal muscle [16].

Large bladder capacity, reduced sensation, increased maximal urethral closure pressure (MUCP), and detrusor underactivity constitute the urodynamic characteristics of Fowler's syndrome [17]. Increased urethral afferent activity most likely inhibits the bladder afferent signals from reaching the brain by potentiating a spinal mechanism of urinary continence. During the filling phase, strong urethral afferent signals are generated. They reduce the signal transmission to the periaqueductal grey (PAG) and higher centers by inhibiting bladder afferent activity in the sacral cord. Thus, the increased activity of the striated urethral sphincter leads to halted voiding [18] (Figure 2).

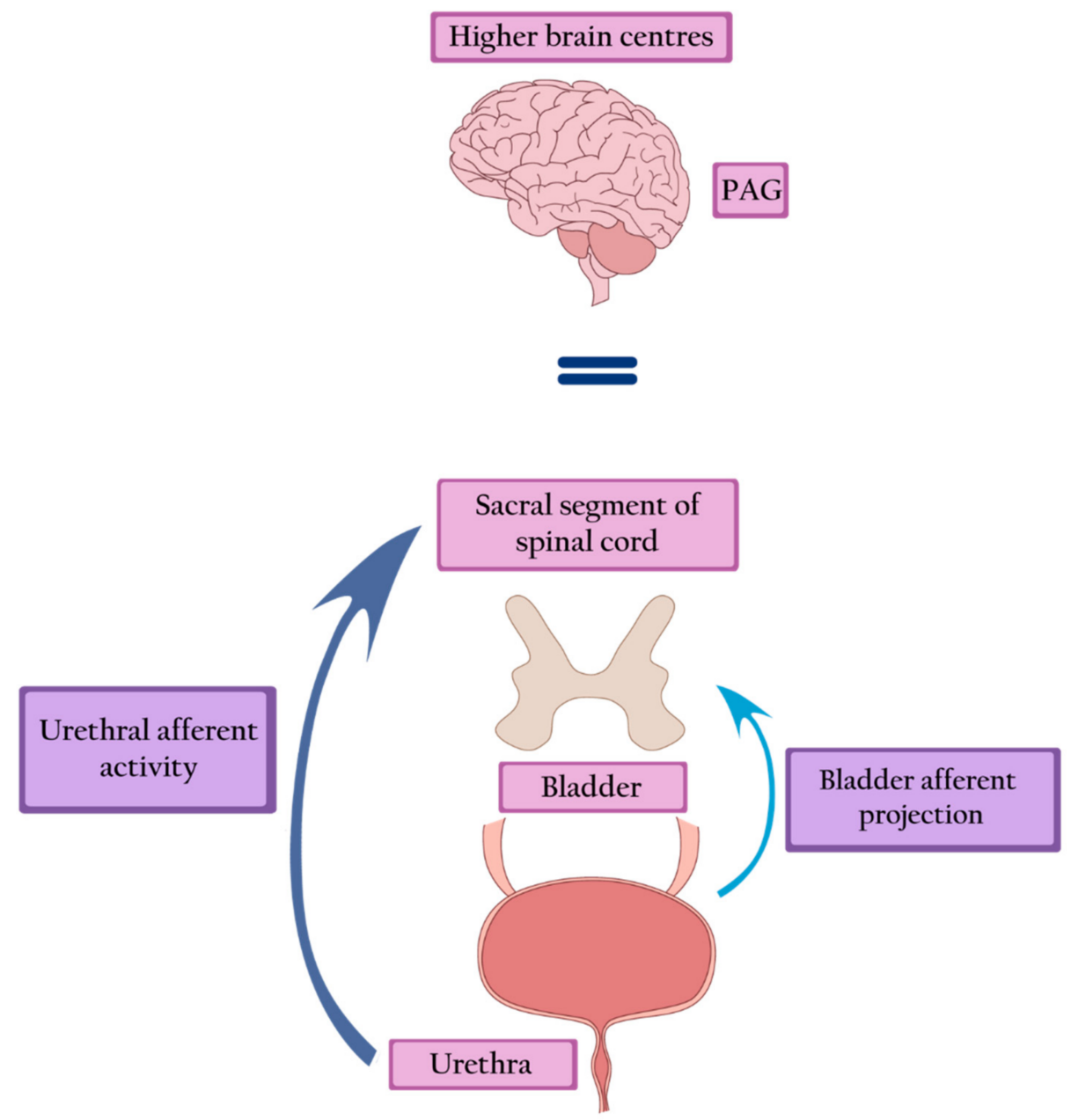

Figure 2. Fowler's syndrome-strong afferent signals generated by the urethra inhibit the afferent activity of the bladder, leading to inactivation of the PAG and higher brain centers. PAGperiaqueductal grey. 


\subsection{Neuroimaging Studies}

The hypothesis described above has been supported by two functional neuroimaging studies which have demonstrated improper brain activity in response to bladder filling in patients with Fowler's syndrome. Dasgupta and colleagues used positron emission tomography (PET) in women with Fowler's syndrome and healthy controls to identify the regions of brain activity that are responsible for the perception of bladder fulness and their modulation by sacral nerve stimulation [19]. They demonstrated that bladder fullness in healthy females is associated with enhanced activity within the brainstem (midbrain and pons) and the anterior and posterior cingulate cortices. Interaction between these structures is essential for the control of micturition. Brainstem regions provide the first level of supraspinal control of urinary function. The PAG receives afferent signals from the sacral spinal cord and thereby communicates with the efferent pontine micturition center. Subsequently, the pontine micturition center projects to the sacral parasympathetic preganglionic neurons.

Moreover, this brain imaging study revealed that the representation of bladder fullness is not solely localized to the PAG. Despite this, the activated area may be more diffused, involving other midbrain regions such as the substantia nigra. Neurons located in the substantia nigra and ventral tegmentum respond to bladder filling and support the micturition reflex. The PAG, the substantia nigra, and the ventral tegmental area are involved in a complicated network of brain centers. The anterior cingulate cortex (ACC) and posterior cingulate cortex (PCC) are essential parts of this network. The ACC likely supports the integration of visceral afferent information. It facilitates an autonomic and motor response through a combination of internal motivations and external behavioral signals. The posterior cingulate cortex (PCC) plays a complementary role in relation to bladder filling. It is suggested that the function of the ACC is primarily executive, whereas the PCC has been defined as more evaluative [20]. It is plausible that the PCC may prevent the bladder overfilling by supporting a motivational representation of bladder extension, leading to micturition.

In contrast to this study, other research utilizing functional magnetic resonance imaging (fMRI) showed widespread negative responses to bladder infusion in women with FS, which were different from activation in healthy individuals. At baseline, with an empty bladder, the brain response to bladder filling was predominantly negative. Furthermore, this negative response was enhanced by the increase in the maximum urethral closure pressure (MUCP), resulting in the deactivation of centers in the midbrain and cortex. These findings support the hypothesis that afferent signals from the bladder are inhibited in women with FS and never reach the PAG [18].

\subsection{Animal Models}

Recently published studies on the feline model have contributed to a more accurate understanding of the pathogenesis of nonobstructive urinary retention (NOUR). Li et al. [21] showed that the abnormal somatic stimulation of afferent axons in the tibial nerve leads to a NOUR that persists for more than 2 hours after the end of stimulation. This observation confirms that the pathophysiology of Fowler's syndrome is associated with the tonic, afferent activation of the pudendal nerve arising in the external urethral sphincter (EUS). It is important to note that the modulatory effect of tibial nerve stimulation (TNS) is frequency-dependent. The urinary retention obtained by the $5-\mathrm{Hz}$ TNS is partially reversed at $1-\mathrm{Hz}$ TNS. Thus, the voiding reflex in the CNS can be inhibited or induced by modulating signals in the tibial afferents. To reflect the pathophysiology of Fowler's syndrome more accurately, another animal model was created in which pudendal nerve stimulation (PNS) was performed. The persistence of the bladder underactivity depended on the time and intensity of the stimulation. Short-term PNS resulted in the rapid disappearance of bladder inactivity, while prolonged PNS at a higher intensity resulted in bladder inactivity lasting for $1.5-2 \mathrm{~h}$ after the cessation of stimulation. The study results confirmed the inhibitory effect of pudendal nerve stimulation on the micturition reflex. Moreover, it has been 
shown that not only tonic but also intermittent afferent activity can generate long-lasting inhibition of bladder contraction. Both PNS and TNS induce bladder inactivity, confirming that prolonged somatic afferent activity may be the pathophysiological cause of NOUR. The advantage of the presented animal models is the maintenance of neural control over the bladder, which makes them more compatible with the real idiopathic underactive bladder [22].

\subsection{Treatment}

Sacral neuromodulation is defined as the permanent electrical stimulation of the sacral segment of the spinal cord that controls the functioning of the bladder and pelvic floor. It restores the balance in the transmission of signals between the pelvic organs, the spinal cord, and the higher centers of the central nervous system [23]. Sacral neuromodulation is the only intervention that can restore a typical voiding pattern in women with Fowler's syndrome. Brain imaging studies show the restoration of the midbrain and pontine activity, as well as the normalization of the signal transfer between the brainstem and the cortex. Moreover, SNM attenuates anterior cingulate activity, thus restoring the desire and ability to void [19]. Presumably, by stimulating neurons in the spinal cords, SNM blocks the inhibition of spinal information transfer from the bladder [18] (Figure 3).

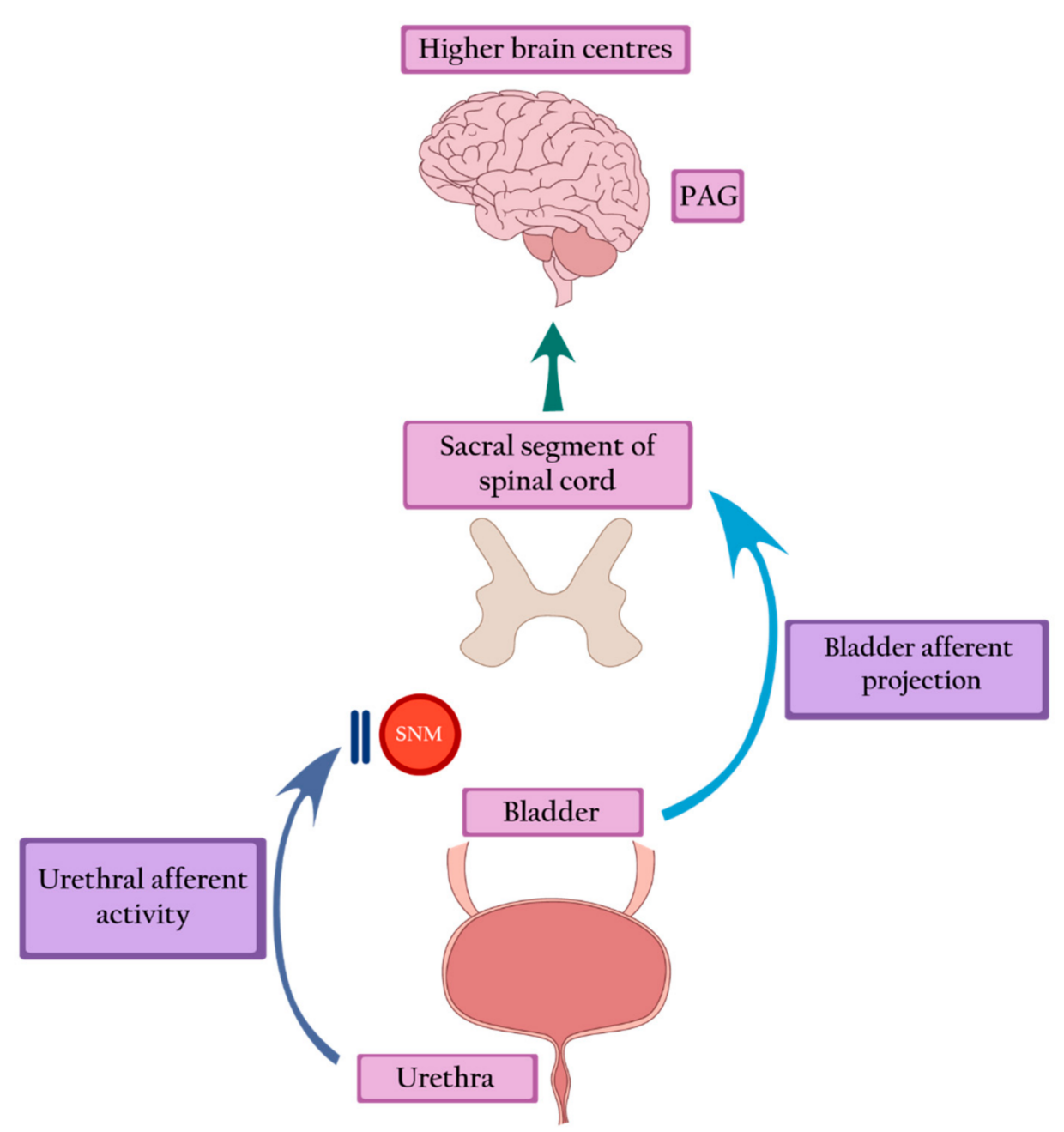

Figure 3. Sacral neuromodulation blocks urethral inhibition and restores bladder afferent projection, leading to the return of bladder sensation and activation of the PAG. PAG-periaqueductal grey, SNM-sacral neuromodulation.

However, the urodynamic evaluation of SNM therapy raises questions concerning a direct afferent effect. Although SNM restores normal voiding, it does not have a direct 
relaxant effect on the EUS. No changes have been demonstrated in EMG and MUCP before and after implantation (MUCP $92.9 \mathrm{~cm} \mathrm{H}_{2} \mathrm{O}$ pre-SNM vs. 84.9 after stimulation, $p=0.06$ ). As the abnormality persists, many of the patients void in an obstructed manner. Uroflowmetry shows an interrupted stream. Surprisingly, cystometry fails to reveal significantly elevated detrusor pressure, as could be expected due to a chronically unrelaxed sphincter. A modest increase in detrusor pressure is most likely sufficient in overcoming urethral resistance. The impact of SNM on detrusor contraction is consistent with its inhibiting effect on urethral afferent activation [17]. This hypothesis was confirmed by an animal study which showed that sacral neuromodulation could partially suppress or completely block the increase in bladder capacity induced by pudendal nerve stimulation [24]. In this context, voiding restoration seems to be achieved through a combination of spinal and supraspinal mechanisms. The clinical efficacy of SNM in the treatment of urinary retention was confirmed in several trials. Swinn et al. (2000) showed a $68 \%$ success rate, yet a relatively high reoperation rate of $21 \%$ [25]. Another study demonstrated the efficacy of SNM in $77 \%$ of patients at a 5-year follow-up. Shortly after implantation, $96 \%$ of subjects (25 patients) voided. However, two had their stimulator deactivated within five years due to pregnancy, and a further three reported loss of efficacy. The revision rate was $54 \%$, and the most common complications included loss of effectiveness, implant-related discomfort, and leg pain [17]. The next study reported twelve years of experience in SNM therapy offered to the women with nonobstructive urinary retention, based on 27 individuals with a median follow-up of 5.7 years. A success rate of $70.83 \%$ was reflected in the return of spontaneous voiding and reduction of mean postvoid residual (PVR) urine from 402.2 to $28.1 \mathrm{~mL}(p<0.0001)$ [26]. Some hopes in the treatment of Fowler's syndrome have been linked to the injection of botulinum toxin A (BoNT-A) into the external urethral sphincter as a less invasive procedure than SNM. The first transperitoneal 200-U BoNT-A injections performed by Fowler in 1992 were unsuccessful [27]. In the following years, transurethral or periurethral injections of 50-100 U BoNT-A were attempted several times, resulting in an improvement of $37 \%-43 \%$ of female patients. The limitations of the trials were the small size of the study groups, the lack of control groups, various injection techniques, and different doses of BoNT-A [28].

\section{Discussion}

In 1988, Professor Clare J. Fowler and her colleagues described a syndrome in young women who demonstrated urinary retention as the primary symptom, accompanied by an abnormality in electromyography (EMG) of the striated muscle of the urethral sphincter, which was related to a pathological contraction of the muscle $[13,29]$. As this problem is rare, epidemiological data on Fowler's syndrome are scarce. Fowler's syndrome is challenging to diagnose and, therefore, this pathology can often be overlooked. The rarity of Fowler's syndrome limits the organization of extensive clinical trials in order to thoroughly understand its pathophysiology and select the best therapeutic method. There are no prospective, randomized, and controlled trials with a long follow-up period or in-depth diagnostics that would exclude other causes of urinary retention. Multiannual observations relate only to retrospective studies. Brain imaging studies and welldesigned animal research provide a better understanding of the etiology of NOUR. Based on these studies, it seems that the main therapeutic direction should be interference with the bidirectional transmission of external urethral sphincter-central nervous system nerve impulses, in order to reverse or inhibit pathological excitation and reflexes. The role of neurotransmitters should also be considered in future therapeutic options; for example, one hypothesis suggests the upregulation of spinal cord enkephalins in Fowler's syndrome. It is possible that SNM acts through neurotransmitters with an anti-enkephalin effect [9]. The recently published studies on the animal models cited above have demonstrated a long-term inhibitory effect on bladder contractility in the function of the intensity and duration of TNS/PNS. On one hand, such a model makes it possible to conduct further research in order to better understand the pathophysiology of NOUR and to develop 
further therapeutic options; on the other hand, it seems possible to use this model to optimize and individualize SNM therapy in patients with an overactive bladder.

The exact mechanism of action of SNM is not fully understood. However, it seems that due to its high efficiency, it is currently the best therapeutic option to avoid or reduce the number of catheterizations in women with NOUR. SNM has a number of limitations related to the occurrence of complications, such as undesirable change in stimulation, implant site pain, lead migration, therapeutic ineffectiveness, and a lower libido. The revision rate exceeding $50 \%$, caused by side effects, results in the necessity to remove the implant in over $20 \%$ of patients [30-33]. Further limitations of the method include absolute contraindications to its use-including an inadequate clinical response to a therapeutic trial, lack of efficient supportive care, and pregnancy—and relative contraindications, such as established complete spinal cord injury, a severe or rapidly progressive neurological disease, and abnormal sacral anatomy [34]. After all, the high cost of the therapy, reaching GBP 10,000 , is not without significance [35]. However, in a Canadian study, the cost-effectiveness of SNM was higher when compared to BoNT-A injections over a 10-year time horizon [36]. The future of neuromodulation is tempting. Miniaturized, rechargeable devices that are safe during full-body MRI scans are being introduced to the market [37]. It is possible that, in the future, wireless devices generating $\mathrm{kHz}$ frequencies capable of blocking pudendal nerve conduction will also be used in the treatment of detrusor sphincter dyssynergia (DSD) in people with spinal cord injuries [38].

\section{Conclusions}

Urinary retention (including Fowler's syndrome) in young women is complex, poorly understood, and often underdiagnosed due to its rarity. The medical community should be aware of this pathology disrupting the quality of life of young women. Further research should be undertaken to clarify the etiology of FS, as well as to improve and simplify the diagnostic process. Nowadays, SNM is the only therapy that effectively restores voiding in the majority of patients, most likely by reestablishing afferent transmission to the brain. Nevertheless, well-designed, long-term prospective studies comparing SNM with other therapies such as pelvic floor muscle physiotherapy are warranted to offer the best patient-tailored treatment.

Author Contributions: Conceptualization, J.K.S.; methodology, J.K.S. and A.S.-J.; investigation, J.K.S. and A.S.-J.; resources, J.K.S. and A.S.-J.; writing—original draft preparation, J.K.S.; supervision, G.J.; All authors have read and agreed to the published version of the manuscript.

Funding: This research received no external funding.

Institutional Review Board Statement: Not applicable.

Informed Consent Statement: Not applicable.

Data Availability Statement: Not Applicable.

Conflicts of Interest: The authors declare no conflict of interest.

\section{References}

1. Doran, J.M.; Roberts, M. Acute Urinary Retention in the Female. Br. J. Urol. 1975, 47, 793-796. [CrossRef] [PubMed]

2. Klarskov, P.; Andersen, J.T.; Asmussen, C.F.; Brenøe, J.; Jensen, S.K.; Jensen, I.L.; Lund, P.; Schultz, A.; Vedel, T. Acute Urinary Retention in Women: A Prospective Study of 18 Consecutive Cases. Scand. J. Urol. Nephrol. 1987, 21, 29-31. [CrossRef] [PubMed]

3. Özveren, B.; Keskin, S. Presentation and prognosis of female acute urinary retention: Analysis of an unusual clinical condition in outpatients. Urol. Ann. 2016, 8, 444-448. [CrossRef]

4. Podnar, S.; Barbić, M. Non-neurogenic urinary retention (Fowler's syndrome) in Two Sisters. Neurourol. Urodyn. 2006, 25, 739-741. [CrossRef]

5. Osman, N.I.; Chapple, C.R. Fowler's syndrome-A cause of unexplained urinary retention in young women? Nat. Rev. Urol. 2014, 11, 87-98. [CrossRef] [PubMed]

6. Kessler, T.M.; Fowler, C.J. Sacral neuromodulation for urinary retention. Nat. Clin. Pract. Urol. 2008, 5, 657-666. [CrossRef]

7. Trachta, J.; Wachter, J.; Kriz, J. Chronic Urinary Retention due to Fowler's Syndrome. Eur. J. Pediatr. Surg. Rep. 2018, 6, e77-e80. [CrossRef] 
8. Swinn, M.J.; Fowler, C.J. Isolated urinary retention in young women, or Fowler's syndrome. Clin. Auton. Res. 2001, 11, 309-311. [CrossRef]

9. $\quad$ Panicker, J.N.; Game, X.; Khan, S.; Kessler, T.M.; Gonzales, G.; Elneil, S.; Fowler, C.J. The Possible Role of Opiates in Women with Chronic Urinary Retention: Observations from a Prospective Clinical Study. J. Urol. 2012, 188, 480-484. [CrossRef]

10. Fowler, C.J.; Kirby, R.S.; Harrison, M.J. Decelerating burst and complex repetitive discharges in the striated muscle of the urethral sphincter, associated with urinary retention in women. J. Neurol. Neurosurg. Psychiatry 1985, 48, 1004-1009. [CrossRef]

11. Tawadros, C.; Burnett, K.; Derbyshire, L.F.; Tawadros, T.; Clarke, N.W.; Betts, C.D. External urethral sphincter electromyography in asymptomatic women and the influence of the menstrual cycle. BJU Int. 2015, 116, 423-431. [CrossRef]

12. Ramm, O.; Mueller, E.R.; Brubaker, L.; Lowenstein, L.; Kenton, K. Complex Repetitive Discharges-A Feature of the Urethral Continence Mechanism or a Pathological Finding? J. Urol. 2012, 187, 2140-2143. [CrossRef]

13. Goodwin, R.J.; Swinn, M.J.; Fowler, C.J. The neurophysiology of urinary retention in young women and its treatment by neuromodulation. World J. Urol. 1998, 15, 305-307. [CrossRef] [PubMed]

14. Karmarkar, R.; Abtahi, B.; Saber-Khalaf, M.; Gonzales, G.; Elneil, S. Gynaecological pathology in women with Fowler's syndrome. Eur. J. Obstet. Gynecol. Reprod. Biol. 2015, 194, 54-57. [CrossRef]

15. Noble, J.; Dixon, P.; Rickards, D.; Fowler, C. Urethral sphincter volumes in women with obstructed voiding and abnormal sphincter electromyographic activity. Br. J. Urol. 1995, 76, 741-746. [CrossRef] [PubMed]

16. Andrich, D.; Rickards, D.; Landon, D.; Fowler, C.; Mundy, A. Structural Assessment of the Urethral Sphincter in Women with Urinary Retention. J. Urol. 2005, 173, 1246-1251. [CrossRef]

17. DasGupta, R.; Fowler, C.J. Urodynamic Study of Women in Urinary Retention Treated with Sacral Neuromodulation. J. Urol. 2004, 171, 1161-1164. [CrossRef]

18. Kavia, R.; Dasgupta, R.; Critchley, H.; Fowler, C.; Griffiths, D. A functional magnetic resonance imaging study of the effect of sacral neuromodulation on brain responses in women with Fowler's syndrome. BJU Int. 2010, 105, 366-372. [CrossRef] [PubMed]

19. Dasgupta, R.; Critchley, H.D.; Dolan, R.J.; Fowler, C.J. Changes in Brain Activity following Sacral Neuromodulation for Urinary Retention. J. Urol. 2005, 174, 2268-2272. [CrossRef]

20. Vogt, B.A.; Finch, D.M.; Olson, C.R. Functional Heterogeneity in Cingulate Cortex: The Anterior Executive and Posterior Evaluative Regions. Cereb. Cortex. 1992, 2, 435-443. [CrossRef]

21. Li, S.; Browning, J.; Theisen, K.; Yecies, T.; Shen, B.; Wang, J.; Roppolo, J.R.; de Groat, W.C.; Tai, C. Prolonged nonobstructive urinary retention induced by tibial nerve stimulation in cats. Am. J. Physiol. Regul. Integr. Comp. Physiol. 2020, 318, R428-R434. [CrossRef]

22. Mohapatra, A.; Chen, J.; Zhao, J.; Zhong, Y.; Armann, K.; Shen, B.; Wang, J.; Beckel, J.; De Groat, W.C.; Tai, C. Bladder underactivity induced by prolonged pudendal afferent activity in cats. Am. J. Physiol. Regul. Integr. Comp. Physiol. 2021, 321, R80-R87. [CrossRef]

23. Szymański, J.K.; Słabuszewska-Jóźwiak, A.; Zaręba, K.; Jakiel, G. Neuromodulation-A therapeutic option for refractory overactive bladder. A recent literature review. Videosurg. Miniinvasive Tech. 2019. [CrossRef]

24. Li, X.; Uy, J.; Yu, M.; Li, S.; Theisen, K.; Browning, J.; Shen, B.; Wang, J.; Roppolo, J.R.; De Groat, W.C.; et al. Sacral neuromodulation blocks pudendal inhibition of reflex bladder activity in cats: Insight into the efficacy of sacral neuromodulation in Fowler's syndrome. Am. J. Physiol. Regul. Integr. Comp. Physiol. 2018, 314, R34-R42. [CrossRef]

25. Swinn, M.J.; Kitchen, N.D.; Goodwin, R.J.; Fowler, C.J. Sacral Neuromodulation for Women with Fowler's Syndrome. Eur. Urol. 2000, 38, 439-443. [CrossRef] [PubMed]

26. Mehmood, S.; Altaweel, W. Long-term outcome of sacral neuromodulation in patients with idiopathic nonobstructive urinary retention: Single-center experience. Urol. Ann. 2017, 9, 244-248. [PubMed]

27. Fowler, C.J.; Betts, C.D.; Christmas, T.J.; Swash, M. Botulinum toxin in the treatment of chronic urinary retention in women. Br. J. Urol. 1992, 70, 387-389. [CrossRef]

28. Kao, Y.-L.; Huang, K.-H.; Kuo, H.-C.; Ou, Y.-C. The therapeutic effects and pathophysiology of Botulinum Toxin A on voiding dysfunction due to urethral sphincter dysfunction. Toxins 2019, 11, 728. [CrossRef]

29. Fowler, C.J.; Christmas, T.J.; Chapple, C.R.; Parkhouse, H.F.; Kirby, R.S.; Jacobs, H.S. Abnormal electromyographic activity of the urethral sphincter, voiding dysfunction, and polycystic ovaries: A new syndrome? BMJ 1988, 297, 1436-1438. [CrossRef] [PubMed]

30. Al-Zahrani, A.A.; Elzayat, E.A.; Gajewski, J.B. Long-term outcome and surgical interventions after sacral neuromodulation implant for lower urinary tract symptoms: 14-year experience at 1 center. J. Urol. 2011, 185, 981-986. [CrossRef] [PubMed]

31. Siegel, S.; Noblett, K.; Mangel, J.; Bennett, J.; Griebling, T.L.; Sutherland, S.E.; Bird, E.T.; Comiter, C.; Culkin, D.; Zylstra, S.; et al. Five-year follow-up results of a prospective, multicenter study with overactive bladder treated with sacral neuromodulation. $J$. Urol. 2018, 199, 229-236. [CrossRef] [PubMed]

32. Leong, R.K.; Marcelissen, T.A.; Nieman, F.H.; De Bie, R.A.; Van Kerrebroeck, P.E.V.A.; De Wachter, S.G.G. Satisfaction and patient experience with sacral neuromodulation: Results of a single center sample survey. J. Urol. 2011, 185, 588-592. [CrossRef]

33. Abello, A.; Das, A.K. Electrical neuromodulation in the management of lower urinary tract dysfunction: Evidence, experience and future prospects. Ther. Adv. Urol. 2018, 10, 165-173. [CrossRef]

34. Goldman, H.B.; Lloyd, J.C.; Noblett, K.L.; Carey, M.P.; Castaño Botero, J.C.; Gajewski, J.B.; Lehur, P.A.; Hassouna, M.M.; Matzel, K.E.; Paquette, I.M.; et al. International Continence Society best practice statement for use of sacral neuromodulation. Neurourol. Urodyn. 2018, 37, 1823-1848. [CrossRef] [PubMed] 
35. Fletcher, N. An overview of sacral neuromodulation: A treatment for patients with symptoms of lower urinary tract dysfunction. Br. J. Nurs. 2020, 29, 848-856. [CrossRef]

36. Hassouna, M.M.; Sadri, H. Economic evaluation of sacral neuromodulation in overactive bladder: A Canadian perspective. Can. Urol. Assoc. J. 2015, 9, 242-247. [CrossRef] [PubMed]

37. De Wachter, S.; Knowles, C.H.; Elterman, D.S.; Kennelly, M.J.; Lehur, P.A.; Matzel, K.E.; Engelberg, S.; Van Kerrebroeck, P.E. New technologies and applications in sacral neuromodulation: An update. Adv. Ther. 2020, 37, 637-643. [CrossRef]

38. Yang, G.; Wang, J.; Shen, B.; Roppolo, J.R.; De Groat, W.C.; Tai, C. Pudendal nerve stimulation and block by a wireless-controlled implantable stimulator in cats. Neuromodulation 2014, 17, 490-496. [CrossRef] 